\title{
DETERMINAN YANG BERHUBUNGAN DENGAN TINDAKAN SADARI PADA MAHASISWI DI FAKULTAS KESEHATAN MASYARAKAT UNIVERSITAS MULAWARMAN
}

\author{
Hilda Marfu'ah Rozkiah ${ }^{1}$, Ike Anggraeni Gunawan ${ }^{2}$, Annisa Nurrachmawati \\ Fakultas Kesehatan Masyarakat Universitas Mulawarman ${ }^{1,2,3}$ \\ hildamr17@gmail.com¹, ikeanggraeni@fkmunmul.ac.id ${ }^{2}$
}

\begin{abstract}
World Health Organization (WHO) estimates that as much as 8 until 9 percent women suffering from breast cancer and 84 million people died from cancer between 2005-2015. The high incidence and fatality rate of cancer could be minimized with prevention especially implemented by adolescents with health educational backgrounds. The exposures during adolescence known more critical than adult exposures in the development of breast cancer, and the preventive care of the breast programs such as breast self-examination (BSE) should also focus on youth. This study aimed to determine association between knowledge, attitude, information exposure and health workers support with BSE as an early detection of breast cancer in students at the Faculty of Public Health, Mulawarman University. This was an observational study with cross-sectional approach. The subjects were 114 female students chosen by purposive sampling. Data collected by online questionnaire and analyzed using chi-square test. The study showed that there were significant association between information exposure with BSE ( $p$ value <0,001), but there were no significant association between knowledge with BSE ( $p$ value 0,775), no significant association between health worker support with BSE ( $p$ value 0,775 ). The results of this study indicate that the majority of respondents have done BSE, but more than half of respondents still did not routinely do BSE, and as much as 41.2 percent of respondents have never done BSE.
\end{abstract}

Keywords $\quad$ : Adolescent, Breast Cancer, Breast Self-Examination, Early Detection

\begin{abstract}
ABSTRAK
Organisasi Kesehatan Dunia (WHO) mengestimasi 8 sampai 9 persen wanita mengalami kanker payudara serta 84 juta orang meninggal akibat kanker dalam rentang waktu 2005-2015. Tingginya angka kejadian serta kematian kanker dapat diminimalisir dengan upaya preventif. Dalam perkembangan kanker payudara paparan selama masa remaja lebih penting daripada paparan pada dewasa sehingga program pencegahan harus berfokus pada remaja salah satunya dengan pemeriksaan payudara sendiri (SADARI). Upaya tersebut hendaknya dilaksanakan secara dini terutama oleh remaja dengan latar belakang pendidikan kesehatan salah satunya kesehatan masyarakat. Penelitian ini bertujuan untuk mengetahui determinan yang berhubungan dengan tindakan pemeriksaan payudara sendiri (SADARI) sebagai deteksi dini kanker payudara pada mahasiswi di Fakultas Kesehatan Masyarakat Universitas Mulawarman. Penelitian ini merupakan penelitian observasional dengan pendekatan cross-sectional. Subjek penelitian adalah 114 mahasiswi yang dipilih secara purposive. Data dikumpulkan melalui kuesioner online dan dianalisis menggunakan uji chi-square. Hasil penelitian menunjukkan bahwa ada hubungan yang signifikan antara paparan informasi dengan SADARI ( $\mathrm{p}$ value $<0,001$ ), tidak ada hubungan yang signifikan antara pengetahuan dengan SADARI (p value 0,775 ), tidak ada hubungan yang signifikan antara petugas kesehatan dukungan dan SADARI (nilai $\mathrm{p}$ 0,775). Hasil penelitian ini menunjukkan bahwa mayoritas responden sudah pernah melakukan SADARI, namun sebagian responden tidak rutin melakukan SADARI, dan masih terdapat 41,2 persen responden belum pernah melakukan SADARI. Diharapkan tenaga kesehatan dapat meningkatkan pemberian pelayanan dan promosi kesehatan yang berkaitan dengan kanker payudara dan deteksi dini kanker payudara dengan SADARI dalam upaya meningkatkan pengetahuan khususnya bagi mahasiswi.
\end{abstract}

Kata Kunci : Kanker Payudara, Remaja, SADARI, Deteksi Dini 


\section{PENDAHULUAN}

Kanker payudara merupakan tumor ganas yang terbentuk dari sel-sel payudara yang tumbuh dan berkembang tanpa terkendali sehingga dapat menyebar di antara jaringan dan organ di dekat payudara atau ke bagian tubuh lainnya (Ginting, 2019). Kanker payudara di Indonesia berada di urutan kedua sebagai kanker yang paling sering ditemukan pada perempuan, setelah kanker mulut rahim (Anggorowati, 2013). Diperkirakan terdapat 100 penderita baru per 100.000 penduduk setiap tahun, atau dari 237 juta penduduk, ada sekitar 237.000 penderita kanker baru setiap tahun (Kemenkes RI, 2015).

Data terkait kanker di Kalimantan Timur masih terbatas. Data terakhir dari rumah sakit rujukan provinsi Rumah Sakit Umum Daerah Abdul Wahab Sjahranie diketahui bahwa kanker payudara memiliki proporsi tertinggi dibanding jenis kanker lainnya. Tahun 2014 dari 750 pasien rawat inap $28.8 \%$ diantaranya didiagnosis kanker payudara (Noorhidayah, 2015). Meningkatnya angka kejadian kanker payudara yang datang pada stadium lanjut dikarenakan masih kurangnya tingkat kesadaran, pengetahuan, rasa takut tentang terjadinya kanker payudara disertai kurangnya data di Indonesia khususnya di Samarinda, Kalimantan Timur (Rahmawaty et al., 2019).

Strategi penting dalam deteksi dini kanker payudara adalah mamografi dan pemeriksaan fisik payudara oleh dokter atau petugas kesehatan yang kompeten atau pemeriksaan payudara klinis dan pemeriksaan payudara sendiri (SADARI). SADARI merupakan aktivitas di mana wanita memeriksa payudaranya secara teratur untuk mendeteksi adanya pembengkakan atau benjolan yang tidak normal sehingga dapat mencari penanganan medis dengan segera. Diagnosis dini memiliki efek positif pada prognosis dan membatasi perkembangan komplikasi dan kecacatan juga meningkatkan kualitas hidup dan kelangsungan hidup (Ebrahim, 2014). Organisasi Kesehatan Dunia (WHO) merekomendasikan pencegahan kanker sebagai komponen penting dari semua program pengendalian kanker karena sekitar $40 \%$ kematian kematian kanker dapat dicegah. Pemerikasaan payudara sendiri (SADARI) telah dipromosikan selama bertahun-tahun sebagai metode skrining untuk kanker payudara pada tahap awal, untuk mengurangi risiko kematian akibat kanker payudara (Yeshitila et al., 2021).

Data Kemenkes RI (2017), menunjukkan 95.6 persen wanita belum melakukan SADARI namun prevalensi spesifik pada remaja tidak tersedia. Berbagai studi mengungkapkan bahwa prevalensi SADARI pada remaja masih rendah dan dipengaruhi oleh pendidikan, sosial ekonomi dan minimnya pengetahuan (Ashokamala \& Weerakoon, 2020; Birhane et al., 2017; Muhammed Ebrahim, 2014; Mukem et al., 2014). Penelitian lain juga menemukan bahwa petugas kesehatan memiliki peran dan tanggung jawab terhadap kesehatan khususnya pada perempuan yakni pencegahan penyakit kanker payudara dengan upaya deteksi dini dengan SADARI, peran yang dimaksudkan untuk selalu memberikan informasi ataupun pelatihan kepada masyarakat tentang deteksi dini kanker payudara (Sari et al., 2020).

Upaya SADARI hendaknya dilaksanakan secara dini terutama oleh remaja terutama dengan latar belakang pendidikan kesehatan salah satunya kesehatan masyarakat. Keterbatasan pengetahuan kanker payudara dan kurangnya pengetahuan tentang pentingnya pemeriksaan diri menjadi hambatan utama untuk tidak melakukan SADARI. Oleh karena itu studi ini bertujuan untuk mengetahui determinan yang berhubungan dengan tindakan SADARI berdasarkan tingkat pengetahuan, sikap, paparan informasi dan 
dukungan tenaga kesehatan pada mahasiswi di Fakultas Kesehatan Masyarakat Universitas Mulawarman"

\section{METODE}

Penelitian ini dilaksanakan menggunakan pendekatan observasional dengan desain studi cross-sectional. Populasi dalam penelitian ini sebanyak 2019 mahasiswa dengan sampel 114 yang dipilih secara purposive dengan ciri-ciri yaitu merupakan mahasiswi aktif angkatan 2018, 2019, dan 2020 dan bersedia untuk mejadi responden penelitian. Besar sampel dihitung menggunakan rumus uji hipotesis proporsi pada satu populasi (One Tail) dengan $\alpha=5 \%$ dan nilai $P_{1}$ serta $P_{2}$ didapatkan dari hasil penelitian terdahulu (Lemeshow, 1997).

Instrumen yang digunakan dibuat berdasarkan berbagai referensi yang telah diuji validilitas dan reliabilitasnya pada 32 orang dengan nilai validitas diatas 0,349 dan nilai reliabilitas diatas 0,7 . Pengetahuan terdiri dari 12 pertanyaan, Sikap terdiri 13 pertanyaan, keterpaparan informasi 2 pertanyaan dan dukungan kesehatan 12 pertanyaan. Masing-masing variabel dikelompokkan menjadi beberapa kategori bedasarkan nilai rata-rata/ mean. Tingkat pengetahuan terdiri atas tiga kategori yaitu pengetahuan rendah $(\mathrm{x}<4)$, sedang $(4 \leq \mathrm{x}<8)$, dan tinggi $(8 \leq \mathrm{x})$, variabel sikap terdiri atas dua kategori yaitu sikap positif (skor $\geq 32,5$ ) dan sikap negatif (skor < 32,5), variabel keterpaparan informasi dikelompokkan menjadi dua kategori yaitu terpapar $(\mathrm{x}=1)$ dan tidak terpapar $(\mathrm{x}=0)$, untuk variabel dukungan tenaga kesehatan dikelompokkan menjadi dua kategori yaitu dukungan tenaga kesehatan kurang (skor < 12) dan dukungan tenaga kesehatan baik (skor $\geq 12$ ), serta variabel perilaku SADARI dikelompokkan menjadi dua kategori yaitu perilaku SADARI kurang dan perilaku SADARI baik.

$\begin{array}{clr}\text { Data } & \text { dikumpulkan } & \text { dengan } \\ \text { kuesioner } & \text { secara } & \text { online }\end{array}$

kepada mahasiswi Fakultas Kesehatan Masyarakat Universitas Mulawarman dimulai pada 27 April 2021 hingga 02 Mei 2021. Selanjutnya data diolah melalui editing, coding, dan cleaning. Data dianalisis kemudian diinterpretasikan untuk menguji hipotesis yang diajukan.

Analisis data dilakukan untuk menjelaskan atau mendeskripsikan karakteristik determinan yang meliputi pengetahuan, sikap, keterpaparan informasi, dan dukungan tenaga kesehatan. Analisis chi-square dilakukan untuk mengetahui hubungan berbagai determinan dengan perilaku SADARI dengan kemaknaan 0,05 sehingga dapat dikatakan memiliki hubungan yang bermakna jika $\mathrm{p}$ value $<0,05$.

\section{HASIL}

Berikut merupakan distribusi responden berdasarkan karakteristik serta determinan dalam perilaku deteksi dini kanker payudara.

\section{Tabel 1. Distribusi Responden berdasarkan karakteristik dan determinan}

\begin{tabular}{|c|c|c|c|}
\hline No & Karakteristik & $\begin{array}{c}\text { Frekuen } \\
\text { si }(n= \\
114)\end{array}$ & $\begin{array}{c}\text { Persentas } \\
\text { e }(\%)\end{array}$ \\
\hline \multirow[t]{8}{*}{1} & Usia & & \\
\hline & 17 Tahun & 2 & 1.8 \\
\hline & 18 Tahun & 19 & 16.7 \\
\hline & 19 Tahun & 40 & 35.1 \\
\hline & 20 Tahun & 36 & 31.6 \\
\hline & 21 Tahun & 15 & 13.2 \\
\hline & 22 Tahun & 1 & 0.9 \\
\hline & 23 Tahun & 1 & 0.9 \\
\hline \multirow[t]{4}{*}{2} & Angkatan & & \\
\hline & 2018 & 49 & 43.0 \\
\hline & 2019 & 14 & 12.3 \\
\hline & 2020 & 51 & 44.7 \\
\hline \multirow[t]{5}{*}{3} & Tingkat & & \\
\hline & Pengetahuan & & \\
\hline & Rendah & 1 & 0.9 \\
\hline & Sedang & 36 & 31.6 \\
\hline & Tinggi & 77 & 67.5 \\
\hline \multirow[t]{3}{*}{4} & Sikap & & \\
\hline & Negatif & 0 & 0.0 \\
\hline & Positif & 114 & 100 \\
\hline
\end{tabular}


5 Keterpaparan

Informasi

$\begin{array}{lll}\text { Tidak Terpapar } & 34 & 29.8\end{array}$

Terpapar

$80 \quad 70.2$

6 Dukungan Tenaga

Kesehatan

Dukungan $\quad 71 \quad 62.3$

Nakes Kurang

Dukungan

Nakes Baik

7 Perilaku SADARI

$\begin{array}{lll}\text { Kurang } & 47 & 41.2\end{array}$

Baik

$67 \quad 58.8$

Berdasarkan karakteristik responden yang diteliti diketahui proporsi usia tertinggi adalah 19 tahun $(35.1 \%)$ dan proporsi angkatan tertinggi berasal dari angkatan 2020 (44.7\%). Berdasarkan determinan yang berhubungan dengan perilaku deteksi dini kanker payudara dengan SADARI diketahui bahwa mayoritas responden $(67.5 \%)$ memiliki tingkat pengetahuan tinggi, sikap responden seluruhnya (100\%) positif, dan mayoritas responden $(80 \%)$ pernah terpapar informasi tentang SADARI.

Sumber informasi yang mereka dapatkan terbanyak bersumber dari televisi (20.4\%), kader kesehatan (19.9\%), seminar/diskusi ilmiah (16.7\%), koran/majalah (11.3\%), petugas puskesmas $(10.8 \%)$, dan dari sumber informasi lain $(20.9 \%)$ yang meliputi artikel, internet, media sosial, perkuliahan, sekolah, pengajian, leaflet, dan poster. Berdasarkan faktor dukungan tenaga kesehatan mayoritas responden $(71 \%)$ menyatakan kurang dan perilaku responden tentang SADARI mayoritas $(67 \%)$ berperilaku baik. Responden mayoritas $(58.8 \%)$ sudah pernah melakukan SADARI, tetapi sebagian responden $(50 \%)$ tidak rutin melakukan SADARI, dan sisanya $41.2 \%$ responden belum pernah melakukan SADARI.

Tabel 2. Hubungan Berbagai Determinan Terhadap Perilaku Deteksi Dini Kanker Payudara Dengan SADARI

\begin{tabular}{|c|c|c|c|c|c|c|c|}
\hline & \multicolumn{4}{|c|}{ Perilaku } & \multicolumn{2}{|c|}{ Total } & \multirow{2}{*}{$\begin{array}{c}p- \\
\text { value }\end{array}$} \\
\hline & \multicolumn{2}{|c|}{ Kurang } & \multicolumn{2}{|c|}{ Baik } & \multirow[b]{2}{*}{$\mathrm{n}$} & \multirow[b]{2}{*}{$\%$} & \\
\hline & $\mathbf{n}$ & $\%$ & n & $\%$ & & & \\
\hline \multicolumn{8}{|l|}{ Tingkat } \\
\hline \multicolumn{8}{|c|}{ Pengetahuan } \\
\hline Rendah & 1 & 100 & 0 & 0.0 & 1 & 100 & 0.418 \\
\hline Sedang & 16 & 44.4 & 20 & 55.6 & 36 & 100 & \\
\hline Tinggi & 30 & 39.0 & 47 & 61.0 & 77 & 100 & \\
\hline \multicolumn{8}{|c|}{ Keterpaparan } \\
\hline \multicolumn{8}{|c|}{ Informasi } \\
\hline Tidak & 23 & 67.6 & 11 & 32.4 & 34 & 100 & $<0.00$ \\
\hline Terpapar & 24 & 30.0 & 56 & 70.0 & 80 & 100 & \\
\hline Terpapar & & & & & & & \\
\hline \multicolumn{8}{|c|}{ Dukungan Nakes } \\
\hline Kurang & 30 & 42.3 & 41 & 57.7 & 71 & 100 & \multirow{4}{*}{0.775} \\
\hline Baik & 17 & 39.5 & 26 & 60.5 & 43 & 100 & \\
\hline Jumlah & 47 & 41.23 & 67 & 58.7 & 114 & 100 & \\
\hline & & & & 7 & & & \\
\hline
\end{tabular}

Hasil analisis terhadap tingkat pengetahuan, diketahui bahwa proporsi hasil menunjukkan bahwa yang mendominasi adalah responden yang memiliki pengetahuan yang baik dan perilaku SADARI yang baik yaitu 47 responden $(61.0 \%)$. Hasil analisis ( $p$-value 0.418 ) yang menunjukkan bahwa tidak ada hubungan yang bermakna antara tingkat pengetahuan dan perilaku SADARI pada mahasiswi Fakultas Kesehatan Masyarakat Universitas Mulawarman. 
Berdasarkan variabel keterpaparan informasi yang paling mendominasi adalah responden yang terpapar informasi dan memiliki perilaku SADARI yang baik yaitu 56 responden $(70.0 \%)$. Hasil analisis ( $p$-value $<0.001)$ yang menunjukkan bahwa ada hubungan yang bermakna antara keterpaparan informasi dengan perilaku SADARI pada mahasiswi Fakultas Kesehatan Masyarakat Universitas Mulawarman.

Berdasarkan variabel dukungan tenaga kesehatan, hasil menunjukkan bahwa yang mendominasi adalah responden yang menyatakan dukungan tenaga kesehatannya kurang tetapi memilki perilaku SADARI yang baik yaitu 41 responden $(57.7 \%)$. Hasil ( $p$-value 0.775 ) yang menunjukkan bahwa tidak ada hubungan yang bermakna antara dukungan tenaga kesehatan dengan perilaku SADARI pada mahasiswi Fakultas Kesehatan Masyarakat Universitas Mulawarman.

Seluruh responden memiliki sikap positif dan perilaku SADARI yang baik yaitu 67 responden (100\%), sehingga tidak dapat dianalisis karena tidak ada variasi dalam sikap.

\section{PEMBAHASAN}

\section{Hubungan Pengetahuan dengan Perilaku SADARI}

Peningkatan pengetahuan tidak selalu menyebabkan perubahan perilaku, namun perilaku yang didasari dengan pengetahuan akan lebih tahan lama daripada perilaku yang tidak didasari oleh pengetahuan (Juwita et al., 2018). Berdasarkan penelitian yang telah dilakukan pada variabel pengetahuan didapatkan hasil analisis ( $p$-value 0.775 ) yang menunjukkan bahwa tidak ada hubungan yang bermakna antara tingkat pengetahuan dan perilaku SADARI pada mahasiswi Fakultas Kesehatan Masyarakat Universitas Mulawarman.
Hal ini sesuai dengan penelitian yang dilakukan oleh Wantini (2017) yang menunjukkan bahwa tidak ada hubungan antara pengetahuan kanker payudara dengan perilaku SADARI ( $p$-value 0.458). Penelitian yang dilakukan oleh Deska et al., (2019) juga menunjukkan bahwa tidak ada hubungan yang signifikasi antara hubungan pengetahuan tentang kanker payudara dengan perilaku SADARI (periksa payudara sendiri) pada mahasiswi (p-value 0.420). Faktor yang dapat mempengaruhi pengetahuan antara lain pendidikan dan informasi dari media massa. Keduanya mempunyai peran penting dalam mempengaruhi pengetahuan seseorang (Parmin, 2018).

Beberapa studi mengungkap bahwa memang benar bahwa pengetahuan remaja tentang kesehatan sudah tinggi, tetapi praktik mereka masih rendah (Nde et al., 2015). Hal ini berarti bahwa perubahan atau peningkatan pengetahuan masyarakat tentang kesehatan tidak diimbangi dengan perilakunya.

\section{Hubungan Keterpaparan Informasi dengan Perilaku SADARI}

Keterpaparan informasi juga merupakan salah satu faktor yang mempengaruhi perilaku SADARI. Berdasarkan penelitian hasil penelitian yang telah dilakukan pada variabel keterpaparan informasi didapatkan hasil analisis ( $p$-value $<0.001)$ yang menunjukkan bahwa ada hubungan yang bermakna antara keterpaparan informasi dengan perilaku SADARI pada mahasiswi Fakultas Kesehatan Masyarakat Universitas Mulawarman.

Hal ini didukung dengan hasil penelitian yang dilakukan oleh Novasari et al., (2016) yang menunjukkan bahwa ada hubungan bermakna paparan media informasi dengan praktik pemeriksaan payudara sendiri (SADARI) dengan ( $p$ value 0.001). Sejalan pula dengan studi Novasari et al., (2016), yang menyatakan adanya paparan informasi menyebabkan 
remaja tersebut memperoleh informasi lebih banyak dibandingkan mereka yang tidak terpapar media informasi tentang SADARI.

Berbagai studi telah menyatakan pesan yang disampaikan media mempengaruhi pengetahuan, sikap dan perilaku terkait kesehatan pada remaja Seperti hasil studi Logan (2014) pada remaja di Shanghai. Media digital yang dapat diakses melalui internet, secara drastis mengubah cara komunikasi remaja, termasuk dalam hal memperoleh informasi (Guse et al., 2012). Sumber informasi kesehatan yang efektif sangat penting kaitannya dalam meningkatkan pengetahuan dan sikap positif untuk mencegah terjadinya penyebaran penyakit. Informasi dapat berasal dari mana saja baik dari petugas ksehatan, keluarga, teman maupun melalui media massa. Keterpaparan informasi yang didengar, dilihat ataupun dibaca akan dapat meningkatkan pengetahuan dan dapat berpengaruh terhadap tindakan pengambilan keputusan (Parmin, 2018). Oleh karena itu perlu penyebaran terus menerus informasi terkait SADARI melalui berbagai cara seperti media sosial agar informasi yang didapatkan dapat diakses, dilihat, dan didengar dari mana saja.

Selain melalui media sosial atau media online pengetahuan dan sikap yang baik untuk melakukan SADARI akan meningkat jika informasi tersebut disampaikan melalui edukasi oleh teman sebaya dari remaja putri (Andriyan et al., 2020).

\section{KESIMPULAN}

Berdasarkan hasil penelitian dan pembahasan terkait dengan faktor-faktor yang berhubungan dengan tindakan pemeriksaan payudara sendiri (SADARI) sebagai deteksi dini kanker payudara pada mahasiswi Fakultas Kesehatan Masyarakat Universitas Mulawarman dapat ditarik kesimpulan bahwa tidak ada hubungan yang bermakna antara tingkat pengetahuan dan perilaku SADARI pada mahasiswi Fakultas Kesehatan Masyarakat Universitas Mulawarman, ada hubungan yang bermakna antara keterpaparan informasi dengan perilaku SADARI pada mahasiswi Fakultas Kesehatan Masyarakat Universitas Mulawarman, dan tidak ada hubungan yang bermakna antara sikap dan perilaku SADARI pada mahaisiswi Fakultas Kesehatan Masyarakat Universitas Mulawarman.

\section{UCAPAN TERIMAKASIH}

Peneliti mengucapkan terima kasih kepada mahasiswi Fakultas Kesehatan Masyarakat Universitas Mulawarman yang telah bersedia menjadi responden penelitian ini.

\section{DAFTAR PUSTAKA}

Afianty, S. D., Handayani, S., Studi, P., \& Masyarakat, K. (2019). Determinan Perilaku SADARI Remaja Putri Dalam Upaya Deteksi Dini Kanker Payudara Determinant of SADARI Behaviour Young Woman In The Early Detection efforts of Breast Cancer. Arkes Mas, 4(2), 198-203.

Andriyan, A. F., Murni, A. W., \& Fatmadona, R. (2020). Pendidikan Teman Sebaya Meningkatkan Pengetahuan Dan Sikap Remaja Putri. Jurnal Keperawatan Jiwa, 8(4), 451-460.

Anggorowati. (2013). Faktor Risiko Kanker Payudara Wanita. KEMAS: Jurnal Kesehatan Masyarakat, 8(2), 121-126.

Ashokamala, P. B. N., \& Weerakoon, B. S. (2020). Knowledge and awareness of breast cancer risk factors and symptoms among female teachers in selected government schools of the embilipitiya educational zone, Sri Lanka. Malaysian Journal of Medicine and Health Sciences, 16(4), 40-45. 
Birhane, K., Alemayehu, M., Anawte, B., Gebremariyam, G., Daniel, R., Addis, S., Worke, T., Mohammed, A., \& Negash, W. (2017). Practices of Breast Self-Examination and Associated Factors among Female Debre Berhan University Students. International Journal of Breast Cancer, 2017. https://doi.org/10.1155/2017/80262 97

Deska, R., Ningsih, D. A., \& Luviana, L. (2019). Hubungan Pengetahuan Tentang Kanker Payudara Dengan Perilaku SADARI ( Periksa Payudara Sendiri). Jurnal Kesehatan Panca Bhakti Lampung, $\operatorname{VII}(2), 26-33$.

Ginting, L. (2019). Hubungan Pengetahuan Dengan Pemeriksaan Payudara Sendiri (Sadari) Sebagai Deteksi Dini Kanker Payudara Pada Mahasiswa Diii Kebidanan Stikes Murni Teguh. Indonesian Trust Health Journal, 1(2), 44-49. https://doi.org/10.37104/ithj.v1i2.1 1

Guse, K., Levine, D., Martins, S., Lira, A., Gaarde, J., Westmorland, W., \& Gilliam, M. (2012). Interventions using new digital media to improve adolescent sexual health: A systematic review. Journal of Adolescent Health, 51(6), 535-543. https://doi.org/10.1016/j.jadohealth .2012.03.014

Juwita, L., Prabasari, N. A., Studi, P., Keperawatan, I., Katolik, U., \& Mandala, W. (2018). Pengetahuan Pemeriksaan Payudara Sendiri (SADARI) Terhadap Sikap dan Perilaku pada Remaja Putri. Adi Husada Nursing Journal, 4(2), 1117.

Kemenkes RI. (2015). Panduan Nasional Penanganan Kanker Kanker Payudara. Komite Nasional Penanggulangan Kanker (KPKN).

Kemenkes RI. (2017). Panduan Nasional
Penanganan Kanker Kanker Payudara. Komite Nasional Penanggulangan Kanker (KPKN).

Logan, P. G. B. and G. D. (2014). Media's Contribution to Sexual Knowledge, Attitudes and Behaviors for Adolescents and Young Adult in Three Asdian Cities. Bone, 23(1), $1-7$.

https://doi.org/10.1016/j.jadohealth .2011.12.009.Media

Muhammed Ebrahim, S. (2014). Knowledge Of Students Toward Breast Cancer And Breast SelfExamination Practice At High

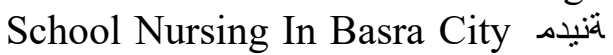

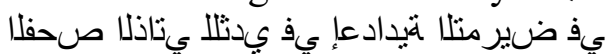

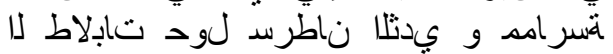
Dr . Samira Muhammed Ebrahim . PhD in Comm. Journal of Kufa for Nursing Science, 4(1).

Mukem, S., Sriplung, H., McNeil, E., \& Tangcharoensathien, V. (2014). Breast cancer screening among women in Thailand: Analyses of population-based household surveys. Journal of the Medical Association of Thailand, 97(11), 1106-1118.

Nde, F. P., Assob, J. C. N., Kwenti, T. E., Njunda, A. L., \& Tainenbe, T. R. G. (2015). Knowledge, attitude and practice of breast self-examination among female undergraduate students in the University of Buea Womens Health. BMC Research Notes, 8(1), 4-9. https://doi.org/10.1186/s13104015-1004-4

Nining Anggraini, N. (2017). Hubungan Karakteristik Dan Dukungan Tenaga Kesehatan Dengan Perilaku Wanita Usia Subur (Wus) Tentang Pemeriksaan Payudara Sendiri (Sadari) Untuk Deteksi Dini Kanker Payudara Di Kelurahan Bulustalan Kota Semarang. Jurnal Kebidanan, 6(2), 68. https://doi.org/10.26714/jk.6.2.201 7.68-73 
Nonik Ayu Wantini, N. I. (2017). Pengetahuan Tentang Kanker Payudara Dan Perilaku Periksa Payudara Sendiri (Sadari) Pada Remaja Putri Di Sma Negeri 1 Turi, Sleman, Diy. Fakultas Ekonomi Dan Bisnis Islam, November, 476-486.

Noorhidayah. (2015). Faktor-Faktor Yang Berhubungan Dengan Kejadian Penyakit Kanker Payudara Pada Pasien Yang Di Rawat Di Ruang Kemoterapi Rumah Sakit Umum Daerah Abdul Wahab Sjahranie Samarinda. Tantangan Profesi Keperawatan Menyongsong Dunia Kerja Bertepatan Dengan"era of Asean Economic Community", 27, 6035.

Novasari, D., Nugroho, D., \& Winarni, S. (2016). Hubungan Pengetahuan, Sikap Dan Paparan Media Informasi Dengan Praktik Pemeriksaan Payudara Sendiri (Sadari) Pada Santriwati Pondok Pesantren Al Ishlah Tembalang Semarang Tahun 2016. Jurnal Kesehatan Masyarakat (e-Journal), 4(4), 186-194.

Parmin, J. (2018). Hubungan Pengetahuan dan Sumber Informasi dengan Pelaksanaan Sadari di SMAN Bernas Pangkalan Kerinci. Doppler Universitas Pahlawan Tuanku Tambusai, 2(2), 13-20.

Rahmawaty, S. D., Abidin, Z., \& Paramita, S. (2019). Hubungan FaktorFaktor Treatment Delay Dengan Kasus Kanker Payudara Stadium Lanjut Di Rsud Abdul Wahab Sjahranie Samarinda Tahun 2019 Relationship Between Treatment Delay Factors With Advanced Stage of Breast Cancer Cases At Rsud Abdul Wahab Syahranie Sam. 2(2), 74-81. https://doi.org/10.15294/kemas.v8i 2.2635
Rekiaddin, L. O., \& Anisa, A. (2020). Hubungan antara Pengetahuan dan Dukungan Tenaga Kesehatan dengan Perilaku Pemeriksaan Payudara Sendiri (SADARI) pada Wanita Pasangan Usia Subur (PUS). Perilaku Dan Promosi Kesehatan: Indonesian Journal of Health Promotion and Behavior, 2(2), 31. https://doi.org/10.47034/ppk.v2i2.4 132

Tria, H. N., \& Rosiana. (2020). Study Program Midwifery Tri Mandiri Sakti Institute of Health Sciences Bengkulu Information Sources, Role Of Health Provider, Knowledge of Women Reproductive Age In Doing SADARI In Area Of Anggut Atas Primaty Health Care In Bengkulu City. 10(1), 186-194.

Yeshitila, Y. G., Kassa, G. M., Gebeyehu, S., Memiah, P., \& Desta, M. (2021). Breast self-examination practice and its determinants among women in Ethiopia: A systematic review and metaanalysis. $\quad P L O S \quad O N E, \quad 16(1$ January), 1-25. https://doi.org/10.1371/journal.pon e. 0245252

Sari, P., Sayuti, S., Ridwan, M., 